ERNESTO ANTONIO FIGUERÓ-FILHO'

VANessa Marcon de OliverRa ${ }^{2}$

Artigos originais

Palavras-chaves

Trombofilia/genética

Anticorpos antifosfolipídeos

Pré-eclâmpsia

Gravidez de alto risco

Aborto habitual

Complicações hematológicas na gravidez

Keywords

Thrombophilia/genetics Antibodies, antiphospholipid

Pré-eclampsia

Pregnancy, high-risk

Abortion, habitual

Pregnancy complications, hematologic

\section{Associação entre abortamentos recorrentes, perdas fetais, pré-eclâmpsia grave e trombofilias hereditárias e anticorpos antifosfolípides em mulheres do Brasil Central}

\section{Resumo}

OBJETIVO: verificar a associação entre abortamentos, perdas fetais recorrentes e pré-eclâmpsia grave e a presença de trombofilias hereditárias e anticorpos antifosfolípides em gestantes. MÉTODOS: estudo observacional transversal de 48 gestantes com histórico de abortamentos recorrentes, perdas fetais (Grupo AB), além de pré-eclâmpsia grave (Grupo PE), atendidas no Ambulatório de Gestação de Alto Risco da Faculdade de Medicina (Famed) da Universidade Federal de Mato Grosso do Sul (UFMS) no período de novembro de 2006 a julho de 2007. Rastreou-se a presença de anticorpos antifosfolípides (anticardiolipina lgMe lgG, anticoagulante lúpico e anti- $\beta_{2}$-glicoproteína l) e trombofilias hereditárias (deficiências de proteínas $C$ e $S$, antitrombina, hiperhomocisteinemia e mutação do fator V Leiden) nas gestantes de ambos os grupos. Os exames foram realizados durante o pré-natal. Os dados paramétricos (idade e paridade) foram analisados por meio do teste $\tau$ de Student e os não paramétricos (presença/ ausência de trombofilias hereditárias e anticorpos antifosfolípides, presença/ausência de pré-eclâmpsia grave, perdas fetais e abortamentos de repetição) em tabelas 2X2 utilizando o teste exato de Fisher, considerando significativo $p<0,05$. RESULTADOS: das 48 gestantes, 31 (65\%) foram incluídas no Grupo AB e 17 (35\%) no Grupo PE. Não houve diferença entre a idade materna e o número de gestações entre os grupos. Houve associação significativa entre abortos e perdas fetais recorrentes e a presença de trombofilias maternas $(p<0,05)$. Não se verificou associação significativa do Grupo AB com a presença de anticorpos antifosfolípides. Também não houve associação significativa entre presença de trombofilias hereditárias e anticorpos antifosfolípides e a ocorrência de pré-eclâmpsia grave em gestação anterior. CONCLUSÕES: os dados obtidos sugerem investigação de rotina para trombofilias em pacientes com história de abortamentos recorrentes e perdas fetais em gestações anteriores.

\section{Abstract}

PURPOSE: to verify the association of abortion, recurrent fetal loss, miscarriage and severe pre-eclampsia with the presence of hereditary thrombophilias and antiphospholipid antibodies in pregnant women. METHODS: observational and transverse study of 48 pregnant women with past medical record of miscarriage, repeated abortion and fetal loss story (AB Group) and severe pre-eclampsia (PE Group), attended to in the High Risk Pregnancy Ambulatory of the Faculdade de Medicina (Famed) from the Universidade Federal de Mato Grosso do Sul (UFMS) from November 2006 to July 2007. The pregnant women of both groups were screened for the presence of antiphospholipid antibodies lanticardiolipin lgG and IgM, lupic anticoagulant and anti- $\beta_{2}$-glycoprotein I) and hereditary thrombophilias (protein C and S deficiency, antithrombin deficiency, hyperhomocysteinemia and factor $V$ Leiden mutation). The laboratorial screening was performed during the pregnancy. The parametric data (maternal age and parity) were analyzed with Student's $\tau$ test. The non-parametric data (presence/absence of hereditary thrombophilias and antiphospholipid antibodies, presence/absence of pre-eclampsia, fetal loss, miscarriage and repeated abortion) were analyzed with Fisher's exact test in contingency tables. It was considered significant the association with $p$ value $<0.05$. RESULTS: out of the 48 pregnant women, 31 (65\%) were included in AB Group and 17 (35\%) in PE Group. There was no significant difference between maternal age and parity within the groups. There was significant statistical association between recurrent fetal loss, recurrent abortions and previous miscarriages and maternal hereditary thrombophilias $(p<0.05)$. There was no statistical association between the AB Group and the presence of antiphospholipid antibodies. Neither there were associations of the PE Group with maternal hereditary thrombophilias and the presence of antiphospholipid antibodies. CONCLUSIONS: the data obtained suggest routine laboratorial investigation for hereditary thrombophilias in pregnant women with previous obstetrical story of recurrent fetal loss, repeated abortion and miscarriage.
Correspondência:

Ernesto Antonio Figueiró-Filho Rua Nagib Ourives, 175 , Carandá Bosque I CEP 79032-424 - Campo Grande/MS Fone: (67) 3042-5005/3042-5025/84069261 E-mail: eafigueiro@uol.com.br
' Doutor, Professor do Departamento de Ginecologia e Obstetrícia da Faculdade de Medicina (FAMED) da Universidade Federal de Mato Grosso do Sul - UFMS - Campo Grande (MS), Brasil.

2 Pós-graduanda do Programa de Pós-Graduação em Saúde e Desenvolvimento da Região Centro-Oeste da Faculdade de Medicina (FAMED) da Universidade Federal de Mato Grosso do Sul - UFMS - Campo Grande (MS), Brasil. 


\section{Introdução}

O sucesso da gravidez depende do estabelecimento e da manutenção eficientes do sistema vascular útero-placentário. Durante a gestação, a unidade útero-placentária inicia e modula interação entre o endotélio vascular materno, as células imunocompetentes presentes localmente e os determinantes antigênicos presentes na superfície do trofoblasto, regulando o processo de adesão, ativação e migração celular, via modificações na rede de citocinas locais ${ }^{1}$. A circulação placentária é assegurada por modificações nas artérias espiraladas e pela hipercoagulabilidade gestacional. Deste modo, tem-se a elevação dos fatores pró-coagulantes e redução dos fatores anticoagulantes e da fibrinólise, induzindo estado de hipercoagulabilidade secundária ${ }^{2}$.

A síndrome do anticorpo antifosfolipídeo (SAAF) caracteriza-se pela ocorrência de trombose arterial ou venosa, abortos recorrentes e trombocitopenia, associados à evidência laboratorial de anticorpos antifosfolipídeos. Os anticorpos antifosfolípides incluem imunoglobulinas ( $\mathrm{IgG}$ e IgM) auto-imunes, que reconhecem e ligamse a complexos de proteínas plasmáticas, associadas a fosfolípides de membrana, em testes laboratoriais in vitro ${ }^{3}$. As duas principais proteínas plasmáticas que funcionam como alvos antigênicos nos complexos reconhecidos pelos anticorpos antifosfolípides são a $\beta_{2}$-glicoproteína I e a protrombina (fator II da coagulação). Outras proteínas que podem se ligar a fosfolípides e formar o complexo alvo dos anticorpos antifosfolípides incluem: apolipoproteína $\mathrm{H}$, proteína $\mathrm{C}$, proteína $\mathrm{S}$, anexina $\mathrm{V}$, fator $\mathrm{X}$, cininogênio de alto peso molecular, fator XI e o componente protéico do heparan-sulfato ${ }^{4,5}$. As complicações obstétricas, associadas à SAAF, incluem abortos recorrentes, ocorrência precoce de pré-eclâmpsia e restrição de crescimento intra-uterino (RCIU) $)^{6-8}$.

Trombofilias são desordens hemostáticas nas quais há tendência ao aumento da freqüência de processos tromboembólicos, sendo classificadas em hereditárias e adquiridas ${ }^{2,9}$. Atingem cerca de $15 \%$ da população caucasiana predisposta a processos trombóticos ${ }^{9}$. A maioria dos casos de trombofilias cursa de modo assintomático. Pacientes portadores que apresentem situações de hipercoagulabilidade secundária, a exemplo da gravidez, poderão receber estímulos que resultarão na formação de trombos. Assim, a presença de trombofilias aumenta o estado de hipercoagulabilidade da gestação, causando trombose no leito de vascularização placentária, levando a complicações obstétricas².
São incluídas entre as trombofilias hereditárias as deficiências de antitrombina (antigamente denominada antitrombina III), proteína $C$ e proteína $S$, mutações genéticas do fator V Leiden, gene G20210A da protombina e o gene C677T variante termolábil da enzima metilenotetrahidrofolato redutase ${ }^{10,11}$. As trombofilias adquiridas mais comuns são devidas aos anticorpos antifosfolípides, que incluem o anticoagulante lúpico e os anticorpos anticardiolipina ${ }^{10,11}$. A resistência à proteína $\mathrm{C}$ ativada e a hiper-homocisteinemia são trombofilias derivadas da combinação de fatores hereditários e adquiridos ${ }^{12}$.

Existem divergências quanto aos fatores que conduzem à ocorrência de abortos de repetição, não sendo possível elucidar mais da metade dos $\operatorname{casos}^{8,13}$. Entre as causas propostas, encontram-se alterações cromossômicas (aneuploidias envolvendo os cromossomos 13, 16, 18, 21,22 , x e y) ${ }^{8,14}$, anomalias uterinas (septos, sinéquias etc. ${ }^{8,14,15}$, distúrbios endócrinos (hipertireoidismo, diabete mellitus descompensado, infecções, síndrome de ovários policísticos ${ }^{8,14,15}$ e os estados pró-trombóticos (trombofilias auto-imunes e de origem genética ${ }^{14}$.

Devido ao grande número de complicações obstétricas, muitas vezes sem comprovação diagnóstica apropriada, objetivou-se, com o presente estudo, verificar a associação entre abortamentos recorrentes, perdas fetais e pré-eclâmpsia grave em gestações anteriores e a presença de trombofilias hereditárias (deficiência de antitrombina, proteína $C$ e proteína $S$, mutação no fator $\mathrm{V}$ e hiper-homocisteinemia) e trombofilias adquiridas (SAAF) em pacientes grávidas.

\section{Métodos}

Desenvolvemos um estudo observacional transversal no qual foram incluídas 48 gestantes atendidas no Ambulatório de Gestação de Alto Risco da Faculdade de Medicina (FAMED) da Universidade Federal de Mato Grosso do Sul (UFMS) no período de novembro de 2006 a julho de 2007. Elas foram separadas em dois grupos de estudo, de acordo com os critérios de inclusão para cada um. Os grupos foram nomeados resumidamente de Grupo AB (perdas fetais e abortamento de repetição) e Grupo PE (pré-eclâmpsia grave).

No Grupo $A B$, foram incluídas gestantes com histórico de abortamentos recorrentes, perdas fetais e/ou mau prognóstico fetal em gestações anteriores. Consideraram-se como mau prognóstico fetal a presença de RCIU, o nascimento pré-termo anterior a 36 semanas completas e/ou a admissão do nascituro em Unidade de Terapia Intensiva (UTI) neonatal por período superior a sete dias. Definiu-se como 
abortamento de repetição a ocorrência de dois ou mais abortamentos clinicamente reconhecidos antes da $20^{\circ}$ semana de gestação $0^{8,13}$. Foi considerado como óbito fetal toda perda fetal após a $20^{\circ}$ semana de gestação ou perda fetal com peso superior a $500 \mathrm{~g}^{8,13}$.

No Grupo PE estavam as gestantes com histórico gestacional prévio de pré-eclâmpsia grave, considerada observando anotações de prontuário ou cartão da gestante de duas ou mais aferições de pressão arterial maior que $160 \times 100 \mathrm{mmHg}$ e proteinúria de 24 horas maior ou igual a $300 \mathrm{mg}^{16}$.

Não foram incluídas em quaisquer dos grupos gestantes com histórico concomitante de pré-eclâmpsia grave com óbito fetal em gestação anterior.

Nas pacientes dos Grupos AB e PE, rastreou-se a presença de anticorpos antifosfolípides com a dosagem de anticardiolipina $\operatorname{IgM}$ e IgG, anticoagulante lúpico e anti- $\beta_{2}$-glicoproteína I. A presença de trombofilias hereditárias foi identificada pelas dosagens de proteína C e S da coagulação, antitrombina, homocisteína e pesquisa de mutação Q506 do fator V (fator V Leiden). As dosagens descritas foram realizadas apenas durante o pré-natal, não sendo repetidas no período puerperal.

As pacientes aceitaram participar do estudo e assinaram o termo de consentimento livre e esclarecido (TCLE). O estudo e seu TCLE foram aprovados pelo Comitê de Ética em Pesquisa em Seres Humanos da UFMS.

A pesquisa de anticorpos anticardiolipina $\operatorname{IgM}$ e IgG foi processada pelo método de enzimoimunoensaio (ELISA), seguindo a metodologia sugerida internacionalmente de padronização ${ }^{17}$. Consideraramse os resultados reagentes para IgM e IgG os valores superiores a $11 \mathrm{U}$ MPL. A presença do anticoagulante lúpico foi investigada em três etapas: na primeira, foi realizado o teste de triagem com as técnicas de tempo de tromboplastina parcial ativada (TTPa) e tempo do veneno de víbora Russel diluído (dRWT). Quando se obtinham valores superiores a 1,26 e/ou 1,14 para os testes de TTPa e dRWT, respectivamente, realizou-se a segunda etapa, na qual se procedeu ao teste de TTPa utilizando uma mistura de $50 \%$ de plasma do paciente e $50 \%$ de plasma normal. Não havendo correção, procedeu-se à terceira etapa, que consiste na realização do teste dRWT confirmatório, cujo resultado positivo para anticoagulante lúpico é superior a $1,21^{18}$.

A pesquisa de anticorpos anti- $\beta_{2}$-glicoproteína I foi realizada por ELISA, na qual se consideraram reagentes os valores superiores a $15 \mathrm{U} / \mathrm{mL}^{19}$. Para dosagem de proteína $\mathrm{C}$, foi realizado o método cromogênico ${ }^{19}$, cujo valor de referência é de 70 a $140 \%$ de atividade. Valores inferiores a $40 \%$ de atividade são considerados como deficiência de proteína $\mathrm{C}$.
A dosagem de proteína $S$ foi conduzida pelo método ELISA $^{19}$, com valores de referência entre 55 e $160 \%$ de atividade, considerando como deficiência de proteína $S$ valores inferiores a 55\%. Para dosagem de antitrombina, o método escolhido foi o cromogênico ${ }^{19}$, cujo valor de referência se encontra entre 76 e $122 \%$, sendo considerados deficiência de antitrombina valores inferiores a $76 \%$. Para a dosagem de homocisteína, realizou-se cromatografia líquida de alta pressão (HPLC), com eluição isocrática e detecção fluorimétrica ${ }^{20}$, cujo valor de referência é de 4 a $12 \mu \mathrm{mol} / \mathrm{L}$, sendo considerada a presença de hiper-homocisteinemia quando os resultados foram superiores à $12 \mu \mathrm{mol} / \mathrm{L}$.

A pesquisa de mutação no gene Q506 do fator $\mathrm{V}$ (fator V Leiden) foi conduzida por reação de polimerase em cadeia (PCR), previamente descrita ${ }^{21}$ com suas modificações ${ }^{22}$, sendo considerada positiva a presença de mutação (homozigoto ou heterozigoto).

Consideraram-se portadoras de trombofilias todas as gestantes que apresentaram resultados compatíveis com deficiência de proteína $C$, deficiência de proteína $\mathrm{S}$, deficiência de antitrombina, hiper-homocisteinemia e a presença de mutação no fator V Leiden (heterozigoto ou homozigoto afetado). Consideraram-se portadoras de anticorpos antifosfolípides todas as pacientes que obtiveram resultados reagentes para anticardiolipina $\operatorname{IgM} / \mathrm{IgG}$, anticoagulante lúpico e/ ou anti- $\beta_{2}$-glicoproteína I.

As variáveis paramétricas (idade e paridade) foram expressas pela média \pm um desvio padrão $(\mathrm{dp})$ e comparadas com o teste $t$ de Student. As variáveis não paramétricas (presença/ausência de trombofilias hereditárias e anticorpos antifosfolípides, presença/ ausência de pré-eclâmpsia grave, perdas fetais e abortamentos de repetição) foram avaliadas em tabelas de contingência de dupla entrada, utilizando o teste exato de Fisher para as associações. Considerou-se significativo o valor de $\mathrm{p}<0,05$ em quaisquer testes estatísticos utilizados.

\section{Resultados}

Das 48 gestantes incluídas, 31 (65\%) estavam no Grupo AB e 17 (35\%) foram incluídas no Grupo PE. No Grupo $A B$, a média de idade das gestantes foi de $29,3 \pm 1,1$ anos, com número médio de gestações de $3,2 \pm 0,3$ e número médio de perdas de $1,2 \pm 0,3$. No Grupo PE, a média de idade das pacientes foi de 29,3 $\pm 1,3$ anos, com número médio de gestações de $2,5 \pm 0,3$. Não houve diferença estatisticamente significativa $(\mathrm{p}>0,05)$ entre a idade materna e o número médio de gestações entre os grupos. 
Tabela 1 - Associação entre a presença de trombofilias e história pregressa de abortamentos recorrentes, perdas fetais e pré-eclâmpsia grave em gestação anterior.

\begin{tabular}{lccccc}
\hline \multirow{2}{*}{ Trombofilias } & \multicolumn{1}{c}{ Grupo AB* - Abortamentos recorrentes e/ou perdas fetais em gestações anteriores } & \multicolumn{3}{c}{ Grupo PE** - Pré-eclâmpsia grave em gestação anterior } \\
\cline { 2 - 6 } & \multicolumn{1}{c}{ Sim } & Não & Total & Sim & Não \\
\hline Presente & $13(27 \%)$ & $15(31 \%)$ & $2(4 \%)$ & $13(27 \%)$ & $15(31 \%)$ \\
Ausente & $18(38 \%)$ & $15(31 \%)$ & $33(69 \%)$ & $15(31 \%)$ & $18(38 \%)$ \\
Total & $31(65 \%)$ & $17(35 \%)$ & $48(100 \%)$ & $17(35 \%)$ & $31(65 \%)$ \\
\hline
\end{tabular}

${ }^{*}$ Teste exato de Fisher. $p<0,05 ; R R=1,58 ; I C 95 \%=1,09-2,29 ;{ }^{* *}$ teste exato de Fisher. $p>0,05 ; R R=1,40 ; 1 C 95 \%=0,95-2,07$.

Tabela 2 - Associação entre a presença de anticorpos antifosfolípides e história pregressa de abortamentos recorrentes, perdas fetais e pré-eclâmpsia grave em gestação anterior.

\begin{tabular}{|c|c|c|c|c|c|c|}
\hline \multirow{2}{*}{ Anticorpo antifosfolípide } & \multicolumn{3}{|c|}{ Grupo $A B^{*}-$ Abortamentos recorrentes e/ou perdas fetais em gestações anteriores } & \multicolumn{3}{|c|}{ Grupo $\mathrm{PE}^{* *}$ - Pré-eclâmpsia grave em gestação anterior } \\
\hline & Sim & Não & Total & Sim & Não & Total \\
\hline Presente & $6(13 \%)$ & $1(2 \%)$ & $7(15 \%)$ & $1(2 \%)$ & $6(13 \%)$ & $7(15 \%)$ \\
\hline Ausente & $25(52 \%)$ & $16(33 \%)$ & $41(85 \%)$ & $16(33 \%)$ & $25(52 \%)$ & $41(85 \%)$ \\
\hline Total & $31(65 \%)$ & $17(35 \%)$ & $48(100 \%)$ & $17(35 \%)$ & $31(65 \%)$ & $48(100 \%)$ \\
\hline
\end{tabular}

"Teste exato de Fisher. $p>0,05 ; R R=1,40 ; I C 95 \%=0,95-2,07 ;{ }^{* *}$ Teste exato de Fisher. $p>0,05 ; R R=1,40 ; I C 95 \%=0,95-2,07$.

Tabela 3 - Prevalência de trombofilias nos grupos de estudo.

\begin{tabular}{lcc}
\hline Trombofilia & Grupo AB & $\begin{array}{c}\text { Grupo PE } \\
\text { Pré-eclâmpsia grave em gestação anterior (n/total do grupo) }\end{array}$ \\
\hline Deficiência de proteína S & Abortamentos recorrentes e/ou perdas fetais em gestações anteriores (n/total do grupo) & $6 \%(1 / 17)$ \\
Deficiência de antitrombina III & $32 \%(9 / 31)$ & - \\
Deficiência de proteína C & $16 \%(5 / 31)$ & $6 \%(1 / 17)$ \\
Hiper-homocisteinemia & $13 \%(4 / 31)$ & $6 \%(1 / 17)$ \\
Mutacção do fator V Leiden & $3 \%(1 / 31)$ & - \\
\hline
\end{tabular}

Tabela 4 - Casos de deficiência de antitrombina em pacientes do grupo de estudo AB (abortamentos recorrentes e/ou perdas fetais em gestações anteriores).

\begin{tabular}{|c|c|c|c|c|c|}
\hline Paciente & Idade & Gesta & Para & Aborto & Histórico em gesłação anterior \\
\hline 1 & 24 & 2 & 1 & 0 & RCIU, oligoâmnio e parto pré-termo anterior a 36 semanas completas \\
\hline 2 & 25 & 4 & 0 & 3 & Abortamentos no primeiro trimestre de gestação \\
\hline 3 & 26 & 4 & 0 & 3 & Abortamentos no primeiro trimestre de gestação \\
\hline 4 & 35 & 6 & 0 & 5 & Abortamentos no primeiro trimestre de gestação \\
\hline 5 & 39 & 4 & 3 & 0 & Gestações com parto pré-termo anterior a 36 semanas completas \\
\hline
\end{tabular}

RCIU=restrição do crescimento intra-útero.

A pesquisa de trombofilias hereditárias nas gestantes do Grupo AB observou resultado positivo em $27 \%$ da amostra. Nas pacientes do Grupo PE, a presença de trombofilias foi identificada em $4 \%$ da amostra, conforme descrito na Tabela 1.

A pesquisa de anticorpos antifosfolípides em gestantes com histórico de abortamentos recorrentes e perdas fetais demonstrou resultado positivo em seis gestantes (13\%), enquanto nas gestantes com história de pré-eclâmpsia grave em gestação anterior à presença destes anticorpos foi detectada em apenas uma gestante (2\%), conforme apresentado na Tabela 2.

Nas gestantes do Grupo AB, as trombofilias mais prevalentes foram as deficiências de proteína $\mathrm{S}$ (32\%), antitrombina (16\%) e proteína C (13\%). Nas gestantes do grupo com histórico de pré-eclâmpsia grave, encontraram-se prevalências semelhantes (6\%) para as deficiências de proteína $\mathrm{C}$, proteína $\mathrm{S}$ e hiper-homocisteinemia, conforme dados expostos na Tabela 3.
Houve associação significativa $(\mathrm{p}<0,05)$ entre a presença de trombofilias e a ocorrência de abortamentos recorrentes e perdas fetais (Grupo AB), conforme demonstra a Tabela 1. Não houve associação significativa deste grupo com a identificação de anticorpos antifosfolípides (Tabela 2).

Também não houve associação entre a presença de trombofilias e a identificação de anticorpos antifosfolípides em gestantes do Grupo PE (Tabelas 1 e 2).

\section{Discussão}

Abortamentos recorrentes acometem aproximadamente 12 a $15 \%$ das gestações clinicamente diagnosticadas e afeta $2 \%$ da população em idade reprodutiva ${ }^{13,23}$. Estudos indicam que o risco de novo episódio de abortamento localiza-se em torno de 24 a $29,6 \%$ em mulheres com histórico de um abortamento anterior - 30 a 36,4\% após três casos e 40 a $50 \%$ após quatro episódios de abortamento ${ }^{8,15,24,25}$. 
$\mathrm{Na}$ presente casuística, a presença de anticorpos antifosfolípides foi encontrada em $13 \%$ das pacientes com história de abortamentos recorrentes e perdas fetais, resultado este inferior ao verificado na literatura ${ }^{26,27}$. No grupo de pacientes com história de pré-eclâmpsia grave em gestação anterior, encontrou-se $2 \%$ de prevalência de anticorpos antifosfolípides, não sendo diferente das taxas descritas, as quais variam de 1,8 a $7 \%^{18,28,29}$.

Ensaios laboratoriais identificando a presença sérica de $\beta_{2}$-glicoproteína I são mais sensíveis para a detecção dos anticorpos antifosfolípides comparativamente àqueles utilizando a identificação isolada de anticorpos anticardiolipina ${ }^{30}$. Em mulheres apresentando histórico de abortamentos recorrentes, demonstrou-se que a identificação adicional de anti- $\beta_{2}$-glicoproteína I não seleciona número maior de pacientes, anteriormente apresentando sorologia negativa para o anticorpo anticardiolipina. Deste modo, infere-se que a presença do marcador anti- $\beta_{2}$-glicoproteína I apresente associação com a síndrome antifosfolípide, mas não com perdas fetais recorrentes ${ }^{31}$.

O presente estudo demonstrou que, dentre as trombofilias, a presença das deficiências das proteínas $\mathrm{C}$ e $\mathrm{S}$ e antitrombina foi mais freqüente no grupo de pacientes que apresentavam história de abortamentos recorrentes e perdas fetais, havendo associação significativa entre a presença de fatores trombogênicos e a má história obstétrica deste grupo.

Existem diversos estudos envolvendo a deficiência de proteína $\mathrm{S}$ em pacientes com abortamentos recorrentes, consistindo em descrições de casos isolados de gestantes com abortamento espontâneo e associação com a presença de trombofilias ${ }^{9,21,27}$. Presume-se maior risco de aborto espontâneo quando há deficiência das proteínas $\mathrm{C}$ ou $\mathrm{S}^{32}$. As deficiências de proteínas $\mathrm{C}$ e $\mathrm{S}$ são identificadas na gravidez quando os exames realizados durante o pré-natal demonstram níveis dessas proteínas abaixo dos valores de referência.

Durante a gravidez, há aumento nos níveis de certos fatores de coagulação e simultânea redução nas concentrações de proteínas anticoagulantes e fibrinólise ${ }^{14,26}$. Estas modificações fisiológicas são importantes para minimizar o risco de perda sanguínea, aumentando a ocorrência de fenômenos tromboembólicos, principalmente quando estão associadas a fatores genéticos ou circunstanciais ${ }^{33}$.

Em estudo recente, realizado com 602 pacientes, a prevalência da deficiência de proteína $\mathrm{C}$ atingiu $4,7 \%$ dos pacientes jovens com trombose venosa recorrente, $\mathrm{e}$ a deficiência de proteína $\mathrm{S}$ ocorreu em 3,7\% de pacientes com trombose venosa ${ }^{34}$. Aceita-se a possibilidade de as pacientes que possuem deficiência dessas proteínas desenvolverem abortamentos recorrentes devido à ocorrência de tromboses no leito de implantação placentária. Esta hipótese pode ser aventada pelo presente estudo, considerando o achado de $32 \%$ de exames positivos para deficiência de proteína S e $13 \%$ de positividade para a presença de deficiência de proteína $C$ nas gestantes com abortamentos recorrentes e perdas fetais (Grupo AB).

Também foi observada, nas gestantes do Grupo $A B$, prevalência de $16 \%$ de deficiência de antitrombina, valor mais elevado quando se compara a prevalência desta trombofilia com casuísticas de pacientes com fenômenos trombóticos, gestantes ou não, nas quais as taxas de deficiência de antitrombina variam de 2 a $3 \%{ }^{34}$. Observando detalhadamente os casos de deficiência de antitrombina da presente casuística, notam-se, além do histórico anterior de abortamentos de repetição, situações sugerindo insuficiência placentária, com gênese de RCIU e nascimentos pré-termo (Tabela 4).

Em gestantes com história de tromboembolismo venoso, descreveu-se em estudo semelhante maior prevalência de deficiência de antitrombina (12\%), comparativamente à presença de mutação do fator $\mathrm{V}$ Leiden $(8 \%)^{35}$. Contraditoriamente, foi verificada prevalência três vezes menor da deficiência de antitrombina, quando comparada à presença da mutação do fator V Leiden, em grávidas com histórico de tromboembolismo ${ }^{36}$.

A homocisteína é reconhecida como fator de risco independente para doenças artério-coronarianas, doenças vasculares periféricas e trombose venosa profunda. A hiper-homocisteinemia é causada predominantemente por deficiência dietética de alguns co-fatores necessários para o metabolismo da homocisteína (ácido fólico, vitamina B6 ou vitamina B12). Pode ser também resultado de deficiência genética, na qual a mutação da enzima metiltetrahidrofolato-redutase na posição 677C-T é identificada, dando lugar a enzima termolábil. Esta mutação possui uma prevalência relatada de $12 \%$ para genótipo homozigoto afetado. A préeclâmpsia está associada com a incidência de hiperhomocisteinemia e com o risco elevado de ocorrência de doenças cardiovasculares ${ }^{37}$. Nas gestantes do Grupo $\mathrm{PE}$, identificou-se hiper-homocisteinemia em $6 \%$ da amostra (Tabela 3).

No presente estudo, a positividade de hiper-homocisteinemia em pacientes com história de abortamentos recorrentes, perdas fetais e/ou mau prognóstico fetal foi de $3 \%$. Este valor pode ser considerado baixo, considerando dados na literatura nos quais a incidência de hiper-homocisteinemia em metodologia semelhante foi de $27 \%{ }^{38}$. Entretanto, a presença de hiper-homocisteinemia passa a ter relevância no grupo de pacientes com histórico de abortamentos recorrentes e perdas fetais quando outros fatores trombofílicos são identificáveis neste grupo. 
O principal agente de tratamento da hiper-homocisteinemia é o ácido fólico, com ou sem a adição de vitaminas $\mathrm{B}_{12}$ e $\mathrm{B}_{6}{ }^{39}$. Verificou-se haver redução de $25 \%$ nos valores séricos de homocisteína quando administrado ácido fólico na dosagem de $5 \mathrm{mg} /$ dia. A adição de $0,5 \mathrm{mg} /$ dia de vitamina $\mathrm{B}_{12}$ produziu redução adicional de $7 \%$, enquanto a adição de $16,5 \mathrm{mg} / \mathrm{dia}$ de vitamina $\mathrm{B}_{6}$ não foi significativa para modificar os níveis de homocisteína ${ }^{40}$.

A prevalência da mutação do fator $\mathrm{V}$ de Leiden é extremamente variável em várias populações, sendo descrita prevalência aumentada até sete vezes em indivíduos caucasóides ${ }^{32}$. Estudos indicam associação entre a presença da mutação do fator $\mathrm{V}$ de Leiden e a ocorrência de abortamentos recorrentes ${ }^{25,41,42}$. Contudo, outros autores não demonstraram tal associação ${ }^{43,44}$, confirmando os achados do presente estudo, no qual encontrou-se prevalência de $3 \%$ para a mutação descrita.

A presença da mutação do fator V Leiden e sua associação com pré-eclâmpsia grave é extensamente discutida na literatura ${ }^{2,11,16}$; entretanto, na presente amostra, não foi observada a presença de nenhum caso positivo de mutação do fator V Leiden no grupo de pacientes com história de pré-eclâmpsia grave em gestação anterior.

Em estudo nacional avaliando a prevalência de fatores trombofílicos em 144 mulheres com infertilidade, identificou-se freqüência de $2 \%$ de anticorpos anticardiolipina, $4 \%$ de deficiência de proteína C, $6 \%$ de deficiência de proteína S, 5\% de deficiência de antitrombina e $3 \%$ de mutação do fator $\mathrm{V}$ de Leiden ${ }^{45}$. Comparando os resultados com os obtidos na presente casuística, observa-se que a prevalência encontrada de anticorpos antifosfolípides e trombofilias é maior em pacientes com má história obstétrica do que em mulheres inférteis.

Concluímos que a identificação de pacientes portadores de trombofilias é importante para a prevenção de acidentes tromboembólicos. O presente estudo sugere que mulheres portadoras de trombofilias (deficiência de proteína $\mathrm{S}, \mathrm{C}$ e antitrombina, hiper-homocisteinemia e mutação do fator V Leiden) durante a gestação apresentam associação positiva com maior prevalência de complicações obstétricas e perinatais, como abortamentos recorrentes e perdas fetais.

Os dados obtidos neste trabalho sugerem investigação de rotina para trombofilias em pacientes com história de abortamentos recorrentes e perdas fetais em gestações anteriores, considerando a possibilidade de tratamento com heparina de baixo peso molecular durante a gravidez atual, evitando, assim, os efeitos deletérios da associação entre gravidez e trombofilias.

\section{Referências}

1. Pereira AC, Jesús NR, Lage LV, Levy RA. Imunidade na gestação normal e na paciente com lúpus eritematoso sistêmico (LES). Rev Bras Reumatol. 2005;45(3):134-40

2. Krabbendam I, Franx A, Bots ML, Fijnheer R, Bruinse HW. Thrombophilias and recurrent pregnancy loss: a critical appraisal of the literature. Eur J Obstet Gynecol Reprod Biol. 2005; $118(2): 143-53$.

3. Branch DW, Khamashta MA. Antiphospholipid syndrome: obstetric diagnosis, management, and controversies. Obstet Gynecol. 2003; 101(6):1333-44

4. Greaves M. Antiphospholipid antibodies and thrombosis. Lancet. 1999;353(9161)1348-53

5. Pierangeli SS, Gharavi AE, Harris EN. Experimental thrombosis and antiphospholipid antibodies: new insights. J Autoimmun. 2000; 15(2):241-7.

6. Rai R, Cohen H, Dave M, Regan L. Randomised controlled trial of aspirin and aspirin plus heparin in pregnant women with recurrent miscarriage associated with phospholipid antibodies (or antiphospholipid antibodies). BM. 1997;314(7076):253-7.

7. Rai R. Obstetric management of antiphospholipid syndrome. J Autoimmun. 2000;15(2):203-7.

8. Schust DJ, Hill JA. Abortamento recorrente. In: Berek JS, editor. Tratado de ginecologia. 13a ed. Rio de Janeiro: Guanabara Koogan; 2005. p. 996-1023.
9. Martinelli I, De Stefano V, Taioli E, Paciaroni K, Rossi E, Mannucci PM. Inherited thrombophilia and first venous thromboembolism during pregnancy and puerperium. Thromb Haemost. 2002;87(5):791-5.

10. De Santis M, Cavaliere AF, Straface G, Di Gianantonio E, Caruso A. Inherited and acquired thrombophilia: pregnancy outcome and treatment. Reprod Toxicol. 2006;22(2):227-33.

11. Robertson L, Wu $O$, Langhorne $P$, Twaddle $S$, Clark $P$, Lowe GD, et al. Thrombophilia in pregnancy: a systematic review. $\mathrm{Br} J$ Haematol. 2006;132(2):171-96.

12. Haemostasis and Thrombosis Task Force British Committee for Standards in Haematology. Investigation and management of heritable thrombophilia. Br J Haematol. 2001;1 14(3):512-28.

13. Medeiros SF. Abortamento habitual. In: Federação Brasileira das Associações de Ginecologia e Obstetrícia. Tratado de ginecologia. Rio de Janeiro: Revinter; 2001 . p. 565-76.

14. Balasch J. Antiphospholipid antibodies: a major advance in the management of recurrent abortion. Autoimmun Rev. 2004;3(3):228-33.

15. Mattar R, Camano L, Daher S. Aborto espontâneo de repetição e atopia. Rev Bras Ginecol Obstet. 2003;25(5):331-5.

16. Kupferminc M, Fait G, Many A, Gordon D, Eldor A, Lessing JB. Severe preeclampsia and high frequency of genetic thrombophilic mutations. Obstet Gynecol. 2000;96(1):45-9. 
17. Harris EN. Special report. The Second International Anti-cardiolipin Standardization Workshop/the Kingston Anti-Phospholipid Antibody Study (KAPS) group. Am J Clin Pathol. 1990;94(4):476-84.

18. Triplett DA, Stocker KF, Unger GA, Barna LK. The Textarin/Ecarin ratio: a confirmatory test for lupus anticoagulants. Thromb Haemost. 1993;70(6):925-31.

19. The British Committee for Standards in Haematology. Guidelines on the investigation and management of thrombophilia. J Clin Pathol. 1990;43(9):703-9.

20. Ubbink JB, Hayward Vermaak WJ, Bissbort S. Rapid high-performance liquid chromatographic assay for total homocysteine levels in human serum. J Chromatogr. 1991;565(1-2):441-6.

21. Koeleman BP, Reitsma PH, Allaart CF, Bertina RM. Activated protein $C$ resistance as an additional risk factor for thrombosis in protein C deficient families. Blood. 1994;84(4):1031-5.

22. Grandone E, Margaglione M, Colaizzo D, d'Addedda M, Cappuci $G$, Vecchione $G$, et al. Factor $V$ Leiden is associated with repeated and recurrent fetal losses. Thromb Haemost. 1997;77(5):822-4.

23. Schieve LA, Tatham L, Peterson HB, Toner J, Jeng G. Spontaneous abortion among pregnancies conceived using assisted reproductive technology in the United States. Obstet Gynecol. 2003;101 (5 Pt 1):959-67.

24. Barini R, Couto E, Mota MMM, Santos CTM, Leiber SR, Batista SC. Fatores associados ao aborto espontâneo recorrente. Rev Bras Ginecol Obstet. 2000;22(4):217-23.

25. Couto E, Barini R, Zaccaria R, Annicchino-Bizzacchi JM, Passini Junior R, Pereira BG, et al. Association of anticardiolipin antibody and C677T in methylenetetrahydrofolate reductase mutation in woman with recurrent spontaneous abortions: a new path to thrombophilia? São Paulo Med J. 2005;123(1):15-20.

26. Vora S, Shetty S, Salvi V, Satoskar P, Ghosh K. A comprehensive screening analysis of antiphospholipid antibodies in Indian women with fetal loss. Eur J Obstet Gynecol Reprod Biol. 2007 Jul 16. [Epub ahead of print]

27. Costa OLN, Brandão C, Silva MMR, Pimentel KS, Santiago MB. Anticorpos antifosfolípides em mulheres com antecedentes de perdas gestacionais: estudo caso-controle. Rev Bras Reumatol. 2005;45(3): $119-23$.

28. Lockshin MD. Antiphospholipid antibody syndrome. Rheum Dis Clin North Am. 1994;20(1):45-59.

29. Dreyfus $M$, Hedelin $G$, Kurtnahorsky R, Lehmann M, Viville $B$, Langer $B$, et al. Antiphospholipid antibodies and preeclampsia: a case-control study. Obstet Gynecol. 2001;97(1):29-34.

30. Yamamoto T, Yoshimura S, Geshi Y, Sasamori Y, Okinaga S, Kobayashi T, et al. Measurement of antiphospholipid antibody by Elisa using purified beta 2-glycoprotein I in preeclampsia. Clin Exp Immunol. 1993;94(1):196-200.

31. Lee RM, Emlen W, Scott JR, Branch DW, Silver RM. Anti-beta 2-glycoprotein I antibodies in women with recurrent spontaneous abortion, unexplained fetal death, and antiphospholipid syndrome. Am J Obstet Gynecol. 1999;181(3):642-8.
32. Preston FE, Rosendaal FR, Walker ID, Briet E, Berntorp E, Conard $\mathrm{J}$, et al. Increased fetal loss in women with heritable thrombophilia. Obstet Gynecol Surv. 1997;52(3):155-6.

33. Hellgren M, Svensson PJ, Dahlbäch B. Resistance to activated protein $C$ as a basis for venous thromboembolism associated with pregnancy and oral contraceptives. Am J Obstet Gynecol. $1995 ; 173(1): 210-3$.

34. De Stefano V, Simione P, Rossi E, Tormene D, Za T, Pagnan A, ef al. The risk of recurrent venous thromboembolism in patients with inherited deficiency of natural anticoagulants antithrombin, protein C and protein S. Haematologica. 2006;91 (5):695-8.

35. McColl MD, Ramsay JE, Tait RC, Walker ID, McCall F, Conkie JA, et al. Risk factors for pregnancy associated venous thromboembolism. Thromb Haemost. 1997;78(4): $1183-8$.

36. Meglic L, Stegnar M, Milanez T, Bozic M, Peterlin B, Peternel $P$, et al. Factor $V$ Leiden, prothrombin $20210 G$ a methylenetetrahydrofolate reductase $677 \mathrm{C} \mathrm{T}$ and plasminogen activator inhibitor $4 G / 5 G$ polymorphism in women with pregnancyrelated venous thromboembolism. Eur J Obstet Gynecol Reprod Biol. 2003; 111 (2):157-63.

37. Powers RW, Minich LA, Lykins DL, Ness RB, Crombleholme WR, Roberts JM. Methylenetetrahydrofolate reductase polymorphism, folate, and susceptibility to preeclampsia. J Soc Gynecol Investig. $1999 ; 6(2): 74-9$.

38. Nelen WL, Blom HJ, Steegers EA, den Heijer M, Thomas CM, Eskes TK. Homocysteine and folate levels as risk factors for recurrent early pregnancy loss. Obstet Gynecol. 2000;95(4):519-524.

39. van den Berg $M$, Boers $G H$. Homocystinuria: what about mild hyperhomocysteinaemia? Postgrad Med J. 1996;72(851):513-8.

40. Homocysteine Lowering Trialists' Collaboration. Lowering blood homocysteine with folic acid based supplements: meta-analysis of randomised trials. BM. 1998;316(7135):894-8.

41. Murphy RP, Donoghue C, Nallen RJ, D'Mello M, Regan C, Whitehead AS, et al. Prospective evaluation of the risk conferred by factor $\mathrm{V}$ Leiden and thermolabile methylenetetrahydrofolate reductase polymorphisms in pregnancy. Arterioscler Thromb Vasc Biol. 2000;20(1):266-70.

42. Younis JS, Ohel G, Brenner B, Haddad S, Lanir N, Ben-Ami M. The effect of thrombophylaxis on pregnancy outcome in patients with recurrent pregnancy loss associated with factor $\mathrm{V}$ Leiden mutation. BJOG. 2000;107(3):415-9.

43. Dizon-Townson DS, Kinney S, Branch DW, Ward K. The factor V Leiden mutation is not a common cause of recurrent miscarriage. J Reprod Immunol. 1997;34(3):217-23.

44. Dulícek P, Chrobák L, Kalousek I, Pesavová L, Pecka M, Stránský P. Is factor V Leiden a risk factor for fetal loss? Acta Medica (Hradec Kralove). 1999;42(3):93-6.

45. Soligo AGS, Barini R, Carvalho ECC, Annichino-Bizzacchi J. Prevalência dos fatores trombofílicos em mulheres com infertilidade. Rev Bras Ginecol Obstet. 2007;29(5):235-40. 